\title{
MYCOTIC PNEUMONIA IN A CAPTIVE PIGEON DUE TO AsPergillus Fumigatus
}

\author{
M. Pal \\ Department of Veterinary Public Health, College of Veterinary Science, Anand, Gujarat 388001, India.
}

\begin{abstract}
The etiologic significance of Aspergillus fumigatus, a saprobic organism, has been described in a young pigeon which died due to severe respiratory distress. The fungus was easily demonstrated in the pneumonic lung both by cultural isolation as well as direct microscopy. The bird was kept in captivity and was given mouldy feed. Epidemiological investigation revealed the high concentration of Aspergillus fumigatus in the feed as well as inside the wooden cage. The treatment could not be attempted as the diagnosis was made on post-mortem examination. The growing role of Aspergillus fumigatus as an important opportunistic pathogen should be investigated particularly in the compromised host.
\end{abstract}

\section{Keywords}

Aspergillus fumigatus, captivity, pigeon, pneumonia

\section{Introduction}

Aspergillus fumigatus is the chief etiologic organism of avian and mammalian aspergillosis including man (Smith, 1989; Pal, et al., 1992; Latge, 1999). The disease may also be caused by other species such as Aspergillus chevalieri, A. candidus, A. flavus, A. glaucus, A. nidulans, A. niger, A. terreus and A. sydowii (Smith, 1989; Denning, 1991; Pal, 1991, 1997; Pal \& Torres- Rodriguez, 1990). The available literature reveals great paucity of information on aspergillosis in captive pigeon from India. The present paper, therefore, documents a fatal case of pulmonary aspergillosis in a wild pigeon kept in captivity.

\section{Materials and Methods}

The dead pigeon brought by a bird enthusiast at the Animal Disease Investigation Laboratory, Veterinary Hospital Campus, Motibagh, New Delhi constituted the material for this investigation. The autopsy was performed and the visceral organs were grossly examined. Small pieces of the affected tissues were collected for direct microscopy in wet and $\mathrm{KOH}$ $(15 \%)$ mounts as well as for culture isolation on Sabouraud
Medium and Nutrient Agar (Pal, 1991). The detailed identification of the isolate was made by studying the cultural and morphological characters (Raper \& Fennell, 1965). In order to establish the source of infection, samples from the remnants of the feed eaten by the pigeon were collected in clean polythene bags for the fungus. The petridishes of Rose Bengal Agar were exposed in the wooden cage where the bird was kept. Chemotherapy was not possible as the pigeon was brought in dead condition.

\section{Results}

At autopsy, the bird showed many greyish-white nodules about $1.5-4 \mathrm{~mm}$ diameter in both the lungs. However, no gross lesions could be detected in other internal organs of the pigeon. There was no growth of bacteria on the Nutrient Agar $37^{\circ} \mathrm{C}$. However, the culture of the affected lungs on Sabourud Medium at $37^{\circ} \mathrm{C}$ showed pure growth of the pathogen. The colony initially appeared whitish, which later changed to dark-blue green (smoky) colour. The growth of the fungus in Lactophenol Cotton Blue stain revealed flask-shaped vesicles, phialids, conidia and hyphae. The fresh tissue mounts and $\mathrm{KOH}(15 \%)$ preparations indicated dichotomously branched, separate hyphae with uniform width (3-6 mm). The fungus was recovered in the feed samples on Sabouraud Medium. Aeromycological examination of the bird cage also showed high concentration of Aspergillus fumigatus.

\section{Discussion}

Although aspergillosis is the most common mycosis in avian species, infection usually occurs under conditions of stress, prolonged therapy with broad spectrum antibacterial drugs, immunosuppression, chronic debilitating disease or massive exposure to Aspergillus fumigatus (Kaplan et al., 1975; Cutsem \& Fransen, 1987; Pal, 1992; Marks et al., 1994; Rao \& Acharyjo, 1996). In the present case, the stress on the bird due to captivity and repeated exposure to heavy concentration of the pathogen in the feed and air, are likely to be the main factors that predisposed the pigeon to Aspergillus fumigatus infection.

The direct demonstration of the pathogen in infected lungs, 
isolation of Aspergillus fumigatus in pure culture and luxuriant growth of the fungus on Sabouraud Medium at $37^{\circ} \mathrm{C}$ from the affected lung tissues and the absence of macroscopic lesions in other internal organs of the pigeon suggest that the respiratory tract was the principal port of entry of Aspergillus infection in the present case. However, dissemination of infection involving other visceras such as the brain, kidney, liver, stomach, intestine, etc. are also reported (Smith, 1989; Latge, 1999).

Aspergillus fumigatus is an opportunistic pathogen which grows as a saprobe in moldy hay, decaying vegetation, decomposing wood chips, sewage sludge compost, litter and other natural substrates (Raper \& Fennell, 1965; Pal et al., 1983). The luxuriant and heavy growth of this thermo-tolerant fungus on various natural substrate contaminate the environment by producing large number of small spores which can be easily inhaled by the susceptible host. The epidemiological investigation is imperative to know the source of infection. The pigeon acquired the infection from the mouldy feed which yielded numerous colonies of A. fumigatus.

Aspergillosis in caged and mild birds occurs in sporadic form and fatal epidemics with high mortality are reported in chicks reared on a deep litter system. The disease can be prevented by avoiding the use of moldy feed, removal and burning of contaminated litter, spraying of $1 \%$ copper sulphate in bird pen and daily cleaning of the cages. As aspergillosis has emerged as an important nosocomial mycosis, immunocompromised individuals, children and elderly persons must adopt hygienic measures to check the transmission of the infection through inhalation of conidia from the saprobic reservoirs. It is emphasized that immunosuppresant patients particularly affected with AIDS should avoid contact with diseased caged birds (Pal, 1997).

\section{Acknowledgements}

The author is grateful to the staff of the Disease Investigation Laboratory, Veterinary Hospital Campus, New Delhi and the bird keeper for their kind help and cooperation during the course of this investigation.

\section{References}

Denning, D.W. (1991). Pulmonary aspergillosis in AIDS. New England Journal of Medicine 324: 654-662.

Kaplan, W., P. Arnstein, L. Ajello, F.W. Chander and J. Watts (1975). Fatal aspergillosis in imported pigeons. Mycopathologia 56: 25-29.

Latge, J.P. (1999). Aspergillus fumigatus and aspergillosis. Clinical Microbiology Review 4: 439-456.

Marks, S.L., E.H. Stauber and S.B. Ernstom (1994). Aspergillosis in an Ostrich. Journal of American Veterinary Medical Association 204: 784-785.

Pal, M. (1991). Disseminated Aspergillus terrus infection in a caged pigeon. Mycopathologia 119: 137-139.

Pal, M. (1997). Zoonoses. R.M. Publishers, Delhi, India.

Pal, M., A.S. Bagi and A.S. Deogankar (1992). Pneumomycosis ina feral crow (Corvus branchyrhnchos) due to Aspergillus fumigatus. Verh ber Enkrg Zootier 34: 151-154.

Pal, M., B.S. Mehrotra and B. Singh (1983). Prevalence of Aspergillus fumigatus in various ecological habitats. Veterinary Research Journal 6: 77-80.

Pal, M. and J.M. Torres-Rodriguez (1990). Aspergillus flavus as a cause of pulmonary aspergillosis in an occupational worker. Revista Iberoamericana De Micologia 7: 33-35.

Raper, K.B. and D.I. Fennell (1965). The Genus Aspergillus. Williams and Wilkins, Baltimore, USA.

Rao, A.T. and L.N. Acharyjo (1996). Pathological conditions in aquatic birds at Nandankanan Zoo - an overview. Indian Journal of Veterinary Pathology 20: 115-120.

Smith, J.M.B. (1989). Opportunistic Mycosis in Man and other Animals. C.A.B. International, Wallingford, UK.

van Cutsom, J. and J. Fransen (1987). Fungal infections in captivity - six case reports. Mykosen 30: 166-171. 